\title{
Periodontal management in osteoporosis patients
}

\author{
Fatin Arab Awartani*, Abdallah Fahad Alzamil and Sultan Abdulrahman Alfada \\ ${ }^{1}$ Professor, Department of Periodontics, king Saud University, Riyadh, Saudi Arabia \\ ${ }^{2}$ Dscd perio pg2, KSUMC, Riyadh, Saudi Arabia \\ ${ }^{3} \mathrm{SB}$ perio r3, SFHP, Riyadh, Saudi Arabia
}

\begin{abstract}
Osteoporosis is systemic skeletal disease characterized by low bone mass and micro-architectural deterioration of bone tissue, leading to enhanced bone fragility and a consequent increase in fracture risk.

There are clear Oral manifestations on the periodontium in osteoporosis patients.

A possible pathway in which systemic bone loss may lead to more severe periodontal destruction is that the reduced bone mineral density (BMD), caused by osteoporosis in the alveolar bone, may facilitate local bone resorption caused by the periodontal disease.

Another possibility is that systemic factors of bone remodeling could modify local tissue response to periodontal infection. Accordingly, individuals with systemic bone loss who have periodontitis may react differently to the increased production of cytokines and inflammatory mediators, therefore presenting more severe periodontal disease

The influence of treatment of osteoporosis in periodontal condition shows that patients receiving vitamin D and calcium supplements and bisphosphonates might or might not have better periodontal health than those who do not have.

Therefore, the aim of this paper is to review the relationship between periodontitis \& osteoporosis and the management of patients with both conditions. Methods to review the association between periodontal disease and osteoporosis, an electronic search was performed using PubMed 1990-2017 mainly to search 1) periodontal disease and osteoporosis. 2) osteoporosis effect on periodontal disease.

Around 129 articles were found, around 33 articles were selected. Diagnosis, association Between Osteoporosis and Periodontal Disease, Mechanisms between osteoporosis and periodontitis, relationship Osteopetrosis and Periodontal Treatment and Implant Placement and Maintenance were mainly searched.

Conclusion: Osteoporosis and periodontitis are both diseases with excessive bone resorption. There may be a disruption of the homeostasis involving bone remodeling, hormonal balance, as well as inflammation progression and resolution. Several shared risk factors exist, and their interactive impact is emerging. Well-controlled clinical studies are needed to establish an evidence base for efficient interdisciplinary management of both diseases.
\end{abstract}

\section{Introduction}

Osteoporosis is a condition that weakens bones, making them fragile and more likely to break. It develops slowly over several years and is often only diagnosed when minor fall or sudden impact causes a bone fracture. It has been defined as a skeletal disease characterized by low bone mass, micro-architectural degradation of bone tissue leading to enhanced bone fragility and a consequent increase in fracture risk [1].

One out of two women and one out of five men over the age of 50 are expected to have a bone fracture, as a result of poor health of bones [2]. These fractures could lead to a disability, poor quality of life, and premature mortality [3]. According to the International Osteoporosis Foundation (IOF), it affects almost: one-tenth of women aged 60, one-fifth of women aged 70 years, as well as two-fifths of women aged 80 years [4]. Osteoporosis and low bone mass combined affected approximately 53.6 million (54\%) older US adults in 2010 [5].

The beginning of osteoporosis usually lies undetected until it presents as a fracture after minor trauma and the condition is now seen both in the UK and worldwide as a major problem in health care. In the UK alone over 200000 osteoporotic fractures are sustained each year, with over one-third of all adult women suffering a fracture related to osteoporosis in their lifetime [6].
Studies about the prevalence of this disease in Kingdom of Saudi Arabia (KSA), has shown that among postmenopausal Saudi women 50-80 years of age, $39.5 \%$ had osteoporosis [7]; there were $24.3,62$ and $73.8 \%$ of affected women in the age groups 50-59, 60-69 and 70-80 years, respectively, among Saudi males $21.4 \%$ were osteoporotic [8].

Periodontitis is the inflammation of the supporting tissues of the teeth. Usually a progressively destructive change leading to loss of bone and periodontal ligament. An extension of inflammation from gingiva into the adjacent bone and ligament.

Osteoporosis impact half of elderly over 65 years and periodontal disease affects half of the adult population, therefore the prevalence of osteoporosis and periodontitis are expected to increase as the population advances in age, therefore the aim of this paper is to review the relationship between periodontitis \& osteoporosis and the management of patients with both conditions.

*Correspondence to: Fatin Arab Awartani, Professor, Department of periodontics, king Saud University, Riyadh, Saudi Arabia; E-mail: fawartani@live.com

Received: March 20, 2019; Accepted: March 29, 2019; Published: April 02, 2019 


\section{Methods}

Methods to review the association between periodontal disease and osteoporosis done by an electronic search using PubMed between 1990-2017, the search were mainly limited to review

1)periodontal disease and osteoporosis.

2) osteoporosis effect on periodontal disease.

3) around 129 articles were found.

However, all studies that didn't have direct relationship between periodontal disease and osteoporosis, case series and case report study were excluded from this review, therefore around 33 articles were included.

\section{Periodontitis as Risk Factors}

Periodontitis is a tainted periodontal disease because of specific pathogenic bacteria flora in the subgingival area. It usually induces the gradual alveolar bone resorption and loss of the soft tissue attachment around the teeth due to chronic inflammation. The bony destruction mechanism of periodontitis is a common cause of the tooth loss in adults. The similar clinical sign of osteoporosis and periodontitis is bone resorption in nature. These tow diseases have similar risk factors. Osteoporosis treatment provides protection for periodontitis [9].

When treating men with insufficiency fractures, both general risk factors for osteoporosis and those specific to men should be borne in mind. These include: Hypothyroidism, thyroid dysfunction, a low body mass index, smoking, high alcohol consumption, long-term corticosteroid therapy (>7.5 mg of prednisolone for $>$ six months), physical in activity and diseases which predispose to low bone mass and neuromuscular dysfunction [10].

Up to $40 \%$ of men with severe osteoporosis, however, have no identifiable cause or risk factor to explain their bone loss [11].

Many interventions reduce fracture risk in the general population and can be used for primary and secondary prevention. These strategies include adequate combined calcium and vitamin D intake (calcium alone has not been shown to reduce fractures), antiresorptive therapy, weight-bearing exercise, tobacco avoidance, moderate alcohol intake [12].

Possible pathways that relates osteoporosis to periodontal disease:

A possible pathway in which systemic bone loss may lead to more severe periodontal destruction is that the reduced bone mineral density (BMD), caused by osteoporosis in the alveolar bone, may facilitate local bone resorption caused by the periodontal disease.

Another possibility is that systemic factors of bone remodeling could modify local tissue response to periodontal infection. Accordingly, individuals with systemic bone loss who have periodontitis may react differently to the increased production of cytokines and inflammatory mediators, therefore presenting more severe periodontal disease.

\section{The Diagnosis Of Osteoporosis}

Conventional radiography is not sensitive enough to diagnose osteoporosis, until the total bone density has decreased by $50 \%$ [13]. At this time, the gold standard for osteoporosis diagnosis is the measurement of bone mineral density (BMD) by dual energy $\mathrm{x}$-ray absorptiometry (DXA) DXA uses an x-ray source for BMD measurement and the measurement is expressed as "area density" in units of grams/cm2 [14,15].

\section{The Relationship Between Osteoporosis And Periodontitis}

Osteoporosis has been proposed as a risk factor for periodontal disease, but prospective longitudinal studies are needed to establish a solid cause and effect relationship. Data based on the third National Health and Nutrition Examination Survey (NHANES III) regarding adults above the age of 50 , it is estimated that $13-18 \%$ of women (3-6 $\%$ of men) have osteoporosis in addition to $37-50 \%$ of women and $28-$ $47 \%$ of men who have osteopenia. An established casual relationship would pose these subjects at a higher risk for periodontal bone loss [16] (Figure 1).

Recently, the relationship between osteoporosis and periodontitis is valued gradually.

Since 1960 the association between these 2 bone-loss diseases had been discussed.

In 2007, Gomes-Filho, et al. indicated the close correlation between low skeletal BMD and inter-proximal alveolar bone loss among a large population of postmenopausal women [17]. Other researches also mentioned that postmenopausal women with osteoporosis had higher risk of periodontitis than those who without osteoporosis [17].

Osteoporosis is regarded as a synergistic factor for the progression of alveolar bone loss in postmenopausal women with pre-existed periodontitis during 2 or 3-year follow-up. Although some researches indicated osteoporosis increased the risk of the alveolar bone and tooth loss, osteoporosis and periodontitis were closely related, other studies indicated that there was no significant association between BMD and the severity of periodontal disease [17].

Dodd, et al. in 2013 in 5 longitudinal studies reviewed that $80 \%$ showed an association between osteoporosis and periodontal disease. A relationship between the 2 diseases was demonstrated in $80 \%$ of the 25 cross-sectional studies. All 3 of the case-control studies showed an association. These data suggest a positive association between osteoporosis and periodontal disease [18].

Penoni, et al. in 2017 reviewed the association between osteoporosis and periodontal disease. He found out that The increased production of pro-inflammatory cytokines, such as interleukin IL-1-, IL-6, tumor necrosis factor (TNF) and RANKL, are important factors in the pathogenesis and progression of periodontal disease and osteoporosis [19].

As such, modulation of the expression of these cytokines maybe a possible link between inflammation and bone resorption in osteoporosis and periodontal disease [19].

He also mentioned that Estrogen deficiency has been considered a key factor for the development of osteoporosis. Furthermore, estrogen influences the function of human periodontal ligament cells causing an increase in the OPG expression and a decrease in RANKL. Accordingly, that hormone may play an important protective role in the antiresorptive effects on human alveolar bone [19].

\section{Association Between Osteoporosis And Periodontal Disease}

Vahid Esfahanian, et al. (2012) in his literature review about the association between osteoporosis and periodontal disease he found some studies had positive association (Table 1), while other studies show negative association (Table 2) [20].

In fact, osteoporosis cannot be a definitive factor in the understanding of periodontal disease. Since periodontal diseases 




Figure 1. Schematic illustration of the association between periodontitis and osteoporosis. The diagram highlights the osseous target for periodontal disease (alveolar cortical bone) and osteoporosis (trabecular bone). Shared risk factors and potential mechanisms underlying both diseases are also listed

Table 1. Studies showing a positive association between osteoporosis and periodontal disease

\begin{tabular}{|c|c|c|c|c|}
\hline Author & Population & Study Design & Risk Estimate & Result \\
\hline Kribbs, et al. & $\begin{array}{l}85 \text { osteoporotic women and } 27 \\
\text { normal women }\end{array}$ & Cross-sectional & OR: 2.7 [95\% CI 1.1-6.5] & $\begin{array}{l}\text { Osteoporotic group had less mandibular bone } \\
\text { mass and density }\end{array}$ \\
\hline Jacobes, et al. & $\begin{array}{l}69 \text { women receiving HRT aged } 32- \\
64 \text { at entry }\end{array}$ & Prospective longitudinal study & No OR calculated & $\begin{array}{l}\text { Positive Correlation between spinal dentistry and } \\
\text { mandibular bone mass at the second examination } \\
\text { (average follow-up } 5.1 \text { years) }\end{array}$ \\
\hline Streckfus, et al. & $\begin{array}{l}28 \text { healthy women aged } 23 \text { women } \\
\text { with periodontitis }\end{array}$ & Cross-sectional & OR: 2.74 [95\% CI 1.23-6.12] & $\begin{array}{l}\text { More ABL, more missing teeth, in } \\
\text { postmenopausal women with estrogen deficiency }\end{array}$ \\
\hline Southard, et al. & $\begin{array}{l}61 \text { dentate Caucasian women aged } \\
20 \text { to } 78 \text { years }\end{array}$ & Cross-sectional & OR: 5.3 [95\% CI 2.5-11.3] & $\begin{array}{l}\text { Significant correlation between the dentistry } \\
\text { of maxillary and mandibular alveolar process, } \\
\text { lumber spine, hip and radius }\end{array}$ \\
\hline Jeffcoat, et al. & 158 postmenopausal women & Cross-sectional & OR: 5.23 & $\begin{array}{l}\text { Significant Correlation between hip BMD and } \\
\text { mandibular basal BMD }\end{array}$ \\
\hline Von Wowern, et al. & $\begin{array}{l}112 \text { women with osteoporotic } \\
\text { fractures }\end{array}$ & Cross-sectional & OR: 2.7 [95\% CI 1.1-6.5] & $\begin{array}{l}\text { Greater amounts of loss of attachment in } \\
\text { osteoporotic women with a mean age of } 68\end{array}$ \\
\hline Tezal, et al. & $\begin{array}{l}70 \text { postmenopausal Caucasian } \\
\text { women aged } 51-78\end{array}$ & Cross-sectional & OR: 2.89 & $\begin{array}{l}\text { Mean ABL was significantly correlated with } \\
\text { systemic BMD }\end{array}$ \\
\hline Payne & $\begin{array}{l}41 \text { with normal BMD, } 17 \\
\text { osteoporotic women }\end{array}$ & $\begin{array}{l}\text { 2-year prospective longitudinal } \\
\text { clinical study }\end{array}$ & OR: 1.73 [95\% CI 1.23-2.43] & $\begin{array}{l}\text { Greater ABL, crestal and sub crestal dentistry } \\
\text { loss in the osteoporotic and estrogen deficient } \\
\text { women. }\end{array}$ \\
\hline Reinhardt, et al. & $\begin{array}{l}\text { Women with } 5 \text { years of menopause, } \\
59 \text { with adult periodontitis and } \\
16 \text { non periodontitis. Stratified by } \\
\text { serum estradiol level }\end{array}$ & $\begin{array}{l}2 \text { years prospective longitudinal } \\
\text { study }\end{array}$ & OR: 1.68 & $\begin{array}{l}\text { In non-smoking osteopenic/osteoporotic } \\
\text { Periodontitis patients with estrogen deficiency } \\
\text { had more bleeding on probing and clinical } \\
\text { attachment loss }\end{array}$ \\
\hline Taguchi, et al. & $\begin{array}{l}64 \text { women between the ages } 50 \text { and } \\
70 \text { years }\end{array}$ & Cross-sectional & OR: 2.10 & $\begin{array}{l}\text { Mean alveolar bone level significantly correlated } \\
\text { with systemic BMD }\end{array}$ \\
\hline Grodstein, et al. & 42,171 post-menopausal women & Cross-sectional & OR: 1.35 [95\% CI: $1.14-1.59]$ & $\begin{array}{l}\text { Significant correlation between systemic BMD } \\
\text { and mandibular basal BMD }\end{array}$ \\
\hline
\end{tabular}

Table 2. Studies showing no positive association between osteoporosis and periodontal disease

\begin{tabular}{|c|c|c|c|c|}
\hline Author & Population & Study Design & Risk Estimate & Result \\
\hline Von Wowern, et al. & $\begin{array}{l}52 \text { women with osteoporotic } \\
\text { fractures }\end{array}$ & Cross-sectional & OR: 1.00 [95\% CI: 0.98-1.02] & $\begin{array}{l}\text { Osteoporotic subjects had not less bone mineral } \\
\text { content in their jaw bones }\end{array}$ \\
\hline Shrout, et al. & $\begin{array}{l}65 \text { post-menopausal women with } \\
\text { no or mild periodontitis }\end{array}$ & Cross-sectional & OR: 1.16 [95\% CI: 0.90-1.49] & $\begin{array}{l}\text { Complexity of the trabecular pattern weakly } \\
\text { correlated with lumber spine and femoral BMD }\end{array}$ \\
\hline Elders, et al. & $\begin{array}{l}216 \text { females between } 46 \text { and } 55 \\
\text { years }\end{array}$ & Cross-sectional & OR: 1.46 [95\% CI: $0.97-2.21]$ & $\begin{array}{l}\text { No significant correlation was observed between } \\
\text { probing depth, bleeding on probing, missing } \\
\text { teeth, alveolar bone height and bone mass }\end{array}$ \\
\hline Hildebolt, et al. & $\begin{array}{l}135 \text { postmenopausal women aged } \\
41-70 \text { years, no moderate, severe } \\
\text { periodontitis }\end{array}$ & Cross-sectional & OR: $1.4[95 \%$ CI: $0.6-3.1]$ & $\begin{array}{l}\text { Attachment loss was correlated with tooth loss } \\
\text { but not with BMD }\end{array}$ \\
\hline Weyant, et al. & $\begin{array}{l}292 \text { dentate women (average age } \\
75.5 \text { years) }\end{array}$ & Cross-sectional & OR: $1.56[95 \%$ CI: $0.98-2.02]$ & $\begin{array}{l}\text { No statistically significant association between } \\
\text { periodontal disease and systemic BMD }\end{array}$ \\
\hline Lundstrom, et al. & $\begin{array}{l}15 \text { women with osteoporosis, } 41 \\
\text { women with normal BMD }\end{array}$ & Cross-sectional & OR: $1.3[95 \%$ CI: $0.98-1.02]$ & $\begin{array}{l}\text { No statistically differences in gingival bleeding, } \\
\text { probing pocket depths, gingival recession and } \\
\text { marginal bone level }\end{array}$ \\
\hline
\end{tabular}


are multifactorial and the main factor is microbial plaque. In fact, osteoporosis cannot be the cause of the onset of periodontal disease, but after outbreak of the disease, it may be a predisposing factor in the exacerbation, or persistence of the disease [20].

Oral manifestations on the periodontium in osteoporosis patients:

1. Data indicate a greater propensity to lose alveolar bone in subjects with osteoporosis, especially in subjects with preexisting periodontitis. This would indicate that osteoporosis or low systemic $\mathrm{BMD}$ should be considered a risk factor for periodontal disease progression [20].

2. In a systematic review and meta-analysis indicates that postmenopausal women with osteoporosis or osteopenia may exhibit greater CAL compared with women with normal BMD [9].

3. There is positive association between osteoporosis and periodontal disease. Determining whether this relationship is causal will require more longitudinal studies. Based on these findings, it is recommended that medical and dental professionals enhance their collaborative actions for prevention, evaluation and treatment of oral diseases and osteoporosis, in order to improve the health of these postmenopausal women [18].

4. Following tooth extraction, there is a continuous change in shape of the residual ridge, but whether ridge resorption is exacerbated in osteoporosis is not known.

5. Good primary stability is essential to ensure long-term success of implant therapy, but again opinion is divided on

Whether osteoporosis plays an important role in compromising implant stability. (DEVLIN \& K. HORNER, 2008) however in recent systematic review shows Successful implant therapy is possible in patients receiving antiresorptive therapy. The possibility of osteoarthritis development needs to be explained to the patient. An individual risk assessment is essential, taking the primary disease with the medication and further wound-healing-compromising diseases and medications into account. If possible, bone augmentations should be avoided, and a perioperative anti-microbiological prophylaxis is strongly recommended in these patients.

\section{Prevention}

The strategy to prevent osteoporosis should include [21]:

- Regular physical activity

- Adequate dietary intake of calcium and vitamin-D

- Calcitonin

- Anabolic steroids

- Parathormone

- Fluoride

- Estrogen and Bisphosphonates

\section{Bisphosphonates}

Bisphosphonates are the group of drugs that are used to treat metabolic diseases like osteoporosis, Paget's disease, hypercalcemia of malignancy and multiple myeloma. Main purpose to inhibit bone resorption, disrupts osteoclastic activity \& osteoclast precursors [22].

\section{Mechanism Of Action:}

Inhibit developmental of osteoclasts [23].

Induction of osteoclast apoptosis [24].

Reduction of osteoclast activity [23].

Prevention of developmental of osteoclasts from hematopoietic precursors [25].

Stimulation of production of an osteoclast inhibitory factor [26].

\section{Mechanisms between osteoporosis and periodontitis}

Osteoporosis is a systemic bone resorption disease affecting mostly precancels bone whereas periodontal disease involves local infection of the periodontium that first attacks the cortical bone and results in dimensional changes of the alveolar ridge. There is a possibility that the osteoporotic changes of the alveolar bone directly contribute to premature loss of teeth through noninfectious mechanism. Menopausal effect of women, such as estrogen level reduction that will effect calcium absorption and result in deficiencies are major risk factor for osteoporosis. Reduce level of estrogen also induce osteocyte apoptosis which disrupt the homeostasis of bone. Hormonal changes also effect systemic bone homeostasis and inflammatory responses.

\section{Osteopetrosis And Periodontal Treatment}

Incidents of osteonecrosis of the jaw have been reported in persons using bisphosphonates and undergoing invasive dental treatment procedures, including tooth extractions, dental implants and surgical and nonsurgical periodontal treatment [27].

In routine dental practice clinicians come across many patients who are receiving bisphosphonates as part of their therapy. Most commonly postmenopausal female patient who are receiving bisphosphonates as a treatment for osteoporosis which is very common for their age group, are encountered. These patients are at increased risk of developing osteonecrosis in jaw when any dental treatment is done or patient is suffering from dental disease. So it becomes important to identify such patients and follow a suggested protocol to avoid complications [28].

\section{Management of Periodontal Diseases:}

Summary of recommendations from the American Dental Association Council on Scientific Affairs. In 2011 an oral health program consisting of sound hygiene practices and regular dental care may be the optimal approach for lowering antiresorptive agentinduced osteonecrosis of the jaw (ARONJ) risk. No validated diagnostic technique exists to determine which patients are at increased risk of developing ARONJ. Discontinuing bisphosphonate therapy may not lower the risk but may have a negative effect on low-bone-masstreatment outcomes

Individuals on antiresorptive therapy who have active chronic periodontal diseases should generally receive appropriate forms of nonsurgical therapy, which should be combined with the commonly recommended reevaluation at four to six weeks. This is not to say that surgical procedures are contraindicated in these patients, only that minimization of dentoalveolar manipulation is generally preferred. Because dental extractions constitute a risk factor for BRONJ, patients should be regularly monitored and treated with the goal of preventing progression of periodontal disease to the point where dental extractions are necessary. The goal of surgical periodontal treatment should be to obtain access to root surfaces, and preference should be placed on the use of atraumatic techniques when possible [29]. 
There are no published studies that evaluate the risk of BRONJ or the success of implant treatment following periodontal procedures such as guided tissue regeneration or bone replacement grafts. Use of such techniques should be judiciously considered based on patient need [29].

Primary soft tissue closure following periodontal surgical procedures is desirable, when feasible, though extended periosteal bone exposure for the sake of primary closure may increase, rather than decrease, the risk of BRONJ. Patients without periodontal disease should receive preventive therapy or instruction for prevention of periodontal disease [29].

\section{Implant Placement and Maintenance:}

The risk of BRONJ and/or implant failure in female patients with a history of bisphosphonate use has been examined in several relatively small, short-term studies. Although there are case reports of BRONJ at implant osteotomy sites, the relative scarcity of BRONJ and dental implant failure in bisphosphonate users despite the large number of these patients receiving dental implants is reassuring [29].

Fugazzotto and colleagues noted no BRONJ post-operatically in 61 patients with an average duration of bisphosphonate use of 3.3 years. None of the implants failed in this population [30].

In a population of 101 implants placed in 42 bisphosphonate users (range 6 months to 11 years duration of use prior to implant placement), Bell and Bell observed no BRONJ and a 95\% implant success rate [31].

Using phone and e-mail surveys, Grant and colleagues noted no BRONJ associated with 468 implants placed in 115 bisphosphonate users with a $99.6 \%$ success rate [32].

Koka and colleagues compared 121 implants placed in 55 bisphosphonate users (approximately one third over 5 years of use) with 166 implants placed in 82 non-users.

No BRONJ was observed in either group and the implants in the two groups showed similar profiles with a $99.2 \%$ success rate in bisphosphonate users and a $98.2 \%$ in non-users [33].

Patients may be informed that the risk of BRONJ as a result of antiresorptive therapy is low, and that the success rates of implants placed in bisphosphonate users appears to be no different than the success rates of implants placed in patients without a history of bisphosphonate use in the short-term. Presently, antiresorptive therapy does not appear to be a contraindication for dental implant placement. However, larger and longer-term studies are needed to determine if implants do as well in patients exposed to antiresorptive agents in comparison to those who have not been exposed to these agents [29].

\section{References}

1. [No authors listed] (1991) Consensus development conference: prophylaxis and treatment of osteoporosis. Am J Med 90: 107-110. [Crossref]

2. NIH Consensus Development Panel on Osteoporosis Prevention. (2001) Diagnosis, and Therapy. Osteoporosis prevention, diagnosis, and therapy. JAMA 285: 785795. [Crossref]

3. Maalouf G, Gannage'-Yared MH, Ezzedine J, Larijani B, Badawi S, et al. (2007). Middle East and North Africa consensus on osteoporosis. J Musculoskelet Neuronal Interact 7: 131-143. [Crossref]

4. International osteoporosis foundation (2010) Osteoporosis facts and statistics.

5. Wright NC, Looker AC, Saag KG, Curtis JR, Delzell ES, et al. (2014) The recent prevalence of osteoporosis and low bone mass in the united states based on bone mineral density at the femoral neck or lumbar spine. J Bone Miner Res 29: 2520-256. [Crossref]
6. Royal College of Physicians (1999) London. Osteoporosis: clinical guide- lines for prevention and treatment.

7. El-Desouki MI (2003) Osteoporosis in postmenopausal Saudi women using dual x-ray bone densitometry. Saudi Med J 24: 953-956. [Crossref]

8. El-Desouki MI, Sulimani RA (2007) High prevalence of osteoporosis in Saudi men Saudi Med J 28: 774-777. [Crossref]

9. Penoni DC, Torres SR, Farias ML, Fernandes TM, et al. (2016) Association of osteoporosis and bone medication with the periodontal condition in elderly women. Osteoporos Int 27: 1887-1896. [Crossref]

10. Francis RM, Peacock M, Marshall DH, Horsman A, Aaron JE (1989) Spinal osteoporosis in men. Bone Miner 5: 347-357. [Crossref]

11. Baillie SP, Davison CE, Johnson FJ, Francis RM (1992) Pathogenesis of vertebral crush fractures in men. Age Ageing 21: 139-141. [Crossref]

12. National Osteoporosis Foundation (2010) Clinician's guide to prevention and treatment of osteoporosis. Washington, DC: National Osteoporosis Foundation 1-56.

13. Koduganti RR, Gorthi C, Reddy PV, Sandeep N (2009) Osteoporosis: "A risk factor for periodontitis". J Indian Soc Periodontol 13: 90-96. [Crossref]

14. World Health Organization (1994) Assessment of fracture risk and its application to screening for postmenopausal osteoporosis. Report of a WHO Study Group". World Health OrganTech Rep Ser 843: 1-129. [Crossref]

15. Lane NE (2006) Epidemiology, etiology, and diagnosis of osteoporosis. Am J Obstet Gynecol 194: S3-11. [Crossref]

16. Wang CW (Jeff), McCauley LK (2016) Osteoporosis and Periodontitis. Curr Osteoporos Rep 14: 284-291. [Crossref]

17. Gomes-Filho IS, PassosJde S, Cruz SS, Vianna MI, Cerqueira Ede M, et al. (2007) The association between postmenopausal osteoporosis and periodontal disease. $J$ Periodontol 78: 1731-1740. [Crossref]

18. Dodd DZ, Rowe DJ (2013) The relationship between postmenopausal osteoporosis and periodontal disease. J Dent Hyg 87:336-344. [Crossref]

19. Penoni DC, Anna TherezaThoméLeão, Fernandes TM, Torres SR (2016) "Possible links between osteoporosis and periodontal disease". RevistaBrasileira de Reumatologia 57: 270-277.

20. Esfahanian V, Shamami MS, Shamami MS (2012) Relationship Between Osteoporosis and Periodontal Disease: Review of the Literature. J Dent (Tehran) 9: 256-264 [Crossref]

21. Lindsay R, CosmanF (2005) Osteoporosis, Chapter 333 in Harrison's Principles of Internal Medicine In: Kasper DL, Fauci AS, Longo DL, Braunwald E, Hauser SL, Jameson JL (Eds), McGraw Hill, (16th ed) 2: 2268-2278.

22. Montoya-Carralero JM, Parra-Mino P, Rami 'rez-Ferna ' ndez P, Morata-Murcia IM, Mompea ' n-Gambi 'n Mdel C, et al. (2010) Dental implants in patients treated with oral bisphosphonates: a bibliographic review. Med Oral Patol Oral Cir Bucal 15: e65-e69. [Crossref]

23. Hughes DE, Wright KR, Uy HL, Sasaki A, Yoneda T, et al. (1995) Bisphosphonates promote apoptosis in murine osteoclasts in vitro and in vivo. $J$ Bone Mineral Res 10 : 1478-1487. [Crossref]

24. Sato M, Grasser W (1990) Effects of bisphosphonates on isolated rat osteoclasts as examined by reflected light microscopy. J Bone Miner Res 5: 31-40. [Crossref]

25. Vitte C, Fleisch H, Guenther HL (1996) Bisphosphonates induce osteoblasts to secrete an inhibitor of osteoclast-mediated resorption. Endocrinology 137: 2324-2333. [Crossref]

26. Zambonin G, Colucci S, Cantatore F, Grano M (1998) Response of Human Osteoblast to Polymethylmetacrylate In Vitro. Calcif Tissue Int 62: 362.

27. Jeffcoat M (2005) The association between osteoporosis and oral bone loss. $J$ Periodontol 76: 2125-2132. [Crossref]

28. Sandeep Kalra, Veena Jain (2013) Dental complications and management of patients on bisphosphonate therapy: A review article. J Oral Biol Craniofac Res 3: 25-30. [Crossref]

29. Hellstein JW, Adler RA, Edwards B, Jacobsen PL, Kalmar JR, et al. (2011) Managing the Care of Patients Receiving Antiresorptive Therapy for Prevention and Treatmen of Osteoporosis Recommendations from the American Dental Association Council on Scientific Affairs. 
30. Fugazzotto P, Lightfoot WS, Jaffin R, Kumar A (2007) Implant placement with or without simultaneous tooth extraction in patients taking oral bisphosphonates: Postoperative healing, early follow-up, and the incidence of complications in two private practices. J Periodontol 78: 1664-1669. [Crossref]

31. Bell BM, Bell RE (2008) Oral bisphosphonates and dental implants: a retrospective study. J Oral Maxillofac Surg 66: 1022-1024. [Crossref]
32. Grant BT, Amenedo C, Freeman K, Kraut RA (2008) Outcomes of placing dental implants in patients taking oral bisphosphonates: a review of 115 cases. $J$ Oral Maxillofac Surg 66: 223-230. [Crossref]

33. Koka S, Babu NM, Norell A (2010) Survival of dental implants in post-menopausal bisphosphonate users. J Prosthodont Res 54: 108-111. [Crossref]

Copyright: (O2019 Awartani FA. This is an open-access article distributed under the terms of the Creative Commons Attribution License, which permits unrestricted use, distribution, and reproduction in any medium, provided the original author and source are credited. 